\title{
DA CIRCUNSTÂNCIA DA EDUCAÇÃO, À TRANSFORMAÇÃO DAS CIRCUNSTÂNCIAS
}

\section{J. Barata-Moura*}

Universidade de Lisboa

\section{Submetido 24/03/2018 - Aceito 02/09/2018}

DOI: $10.15628 /$ holos. 2018.7128

\section{RESUMO}

Conferência proferida na abertura do IV Colóquio Instituto Federal do Rio Grande do Norte, em julho de Nacional a Produção do Conhecimento realizado no 2017.

KEYWORDS: Educação, Transformação.

THE CIRCUMSTANCES OF EDUCATION, TO THE TRANSFORMATION OF CIRCUMSTANCES

\section{ABSTRACT}

Opening Conference of the IV National Colloquium for the Production of Knowledge, held at the
Federal Institute of Rio Grande do Norte, in July 2017.

KEYWORDS: Education, Transformation. 


\section{§ 1. Intróito}

Agradeço ao Professor Dante Henrique Moura, e à Organização do Colóquio Nacional A produção do conhecimento em Educação Profissional, a honra do convite para intervir na abertura dos trabalhos, e a hospitalidade amiga com que estou sendo acolhido em Natal.

O Professor Domingos Leite Lima Filho, desde Curitiba, operou a intermediação eficiente, e as Professoras Luísa Cerdeira e Alda Duarte Araújo Castro, em Lisboa, foram incansavelmente eficazes na faina de me convencer a que viesse.

Eu gosto de estar convosco, e de convosco aprender.

O problema que me enrodilha nas reservas é palestrar acerca de coisas que não sei, perante um auditório que sabe. Não tendo, ademais, da realidade brasileira sequer um conhecimento de vivência que habilite a - mesmo debitando disparates - algo de situadamente útil vos trazer à presença do pensar.

Não tomem, por isso, a minha fala como um discurso de especialista (que não sou), como um oráculo de sabedoria (que não possuo), ou como um prontuário de receitas (que também ignoro quais sejam).

Em jornadas de reflexão, importa reflectir.

É, pois, tão-só como modesto exercício introdutório que vos desdobro um balcão de perspectiva para um panorama encrencado de questões, de desafios, de tarefas, que todos vocês - muito melhor do que eu - conhecem: no quotidiano das labutas, na firmeza dos empenhamentos, no processo das feituras em aberto.

Apresentadas as desculpas de um mau palrador, passemos ao esfarrapado lençol da peroração.

\section{§ 2. Circunstâncias tristes.}

Há quem imagine a educação como um mundo à parte: uma miniatura de paraíso artificial, uma gostosa antecâmara protegida, onde é suposto que as criancinhas aprendam a repetir o "dever-ser», numa redoma higienicamente pura, e divorciada do ser (que não são treinadas a cultivar).

Há quem faça do processo «educativo» uma expedita linha de montagem para o ensacamento de linguiças, uma caserna de amestramentos: com pedacinhos de «saber» na tripa embutidos, domesticação de sentimentos e atitudes à mistura, e um prometido "sucesso" na ponta, no caso de os infantes continuarem bem-comportados e obedientes à voz dos donos e dos capatazes do turno.

Para os irrecuperáveis, os desleixados, os renitentes - e, sobretudo, a carga geral dos oriundos da prole dos explorados, ou dos que apenas com intermitência encontram trabalho 
explorável -, a educação dita "escolarizada» torna-se um entreposto: onde se depositam, durante os períodos a que a lei obrigue (e a assiduidade enganada consinta), amontoados contingentes de passageiros em trânsito de uma proveniência que se desconhece (mas adivinha) para um destino que se ignora (mas se prevê sombrio).

Uns, refugiam-se na alimentação generosa de um "sonho» lindo e exemplar - mais "alternativo», do que alterativo -, à margem do corpo escalavrado das realidades dolorosas (que bem basta os meninos terem de algum dia descobrir).

Outros, convertem a formação em dispositivo de "formatação», que acondicione a infantil matéria plástica disponível aos espartilhos de um «real», mostrado e servido apenas na unidimensionalidade soturna do existente dominante.

Os cansados e os desistentes - partilhando uma frustração sentida, mas inatacada resignam-se, na impotência, ao cumprimento (desmazelado, ou indolente) de umas vagas funções de fiel de armazém de inertes (que, por mero acaso, são pessoas).

Todas estas circunstâncias tristes fazem parte da circunstância da educação.

Mas não lhe esgotam nem o teor efectivo, nem o leque das possibilidades reais que, no seu contraditório presente, ela encerra já em latência, e que ao fronteiro, como projecção de forças, vai lançando.

É possível a outra luz pensar a educação.

É possível formar numa outra perspectiva.

E, pelo caminho, é possível transformar talvez as circunstâncias.

O que, no entanto, não está dependente - nem só, nem primeiro - de um aturado esforço «educativo».

É uma ilusão grave supôr que a envencilhada complexidade real dos problemas se resolve com umas respostas simples, e num elegante passe de magia legislativa.

\section{§ 3. No contorno, e na abertura, de um viver.}

A educação dá-se em diferentes espaços:

Dispondo de um guarda-roupa vário na «organização institutional», e ostentando graus diversos de formalidade nos trajectos da trajectória.

Mas o processo formativo opera-se sempre na unidade de um tempo:

Não goza de nenhum estatuto de extra-territorialidade relativamente ao viver concreto.

Educamo-nos de dentro de um mundo - e de dentro de itinerários pessoais - que compartimos:

Na envolvência que sofremos, respiramos, onde agimos. 
Num entramado de relações com outros, que nos funda, e enche de colorido, a própria possibilidade de ser.

Numa modelação de nós mesmos - nem sempre atendida, e entendida - que vamos efectuando no entretecido destas texturas.

A descoberta do mundo e da vida que vamos fazendo - da primeira infância à derradeira velhice -, fazêmo-la em conjunto:

Nas vicissitudes, e com as contradições, deste des-conjuntado complexo de con-vivências relacionais.

Mas, nas geometrias variáveis de um processo educativo - onde a multiplicidade não dispensa o uno, e onde a unidade só é rica quando no seu seio com-porta o múltiplo - vamos dando forma à condução do nosso viver.

E dar forma é trans-formar.

Subjectiva, e objectivamente: os agentes que, na transformação, se formam; e as circunstâncias da formatura que - por grandes (e por humildes) intervenções práticas reconfiguradoras - igualmente são, na sua materialidade, transformáveis.

Não, pela bitola imediata do desejo que palpita.

Não, segundo o ritmo cavalgante da vontade.

Não, pela veemência justamente indignada dos fraseados e das inquietações que do peito nos saltam e pela boca fora se perdem.

Mas, por um quotidiano trabalho endógeno da vida.

Com expressão socialmente organizada: onde o imprescindível empenhamento próprio de cada um tem de ganhar inscrição, em modalidades todavia diversificadas.

Um trabalho que não é fácil:

Onde importa compreender, para transformar; e transformar, compreendendo.

Há decerto aprendizados - teóricos, técnicos, e afectivos - que constituem indispensada ferramenta a pôr a uso nas exercitações diárias.

Deles importa cuidar: com profissionalidade, com discernimento, e com vocação de respiro ao horizonte.

Porque a vida é, toda ela, um processo educativo.

Não, para um viver que «está fora», e «há-de vir» depois.

Mas na lavoura diária de um acontecer determinado, onde - na luta com um insatisfatório estabelecido - se abrem as condições ao trânsito a uma outra configuração do ser. 


\section{§ 4. Tempos de regressão.}

Educamo-nos, nas voltas, e nas reviravoltas, de um tempo que vivemos. Num percurso em que vamos dando a volta aos tempos.

A paisagem não se limita a desfilar. Tem caixilho na janela.

E os tempos que transcorrem representam estações diferentes de uma viagem, que não se faz sem solavanco.

A história anda para diante:

Com o tempo (cronológico) que nos escorre na ampulheta: do minuto que falta para o encontro que se espera, ao século que se arrasta numa modorra que não se sente.

Mas a história não decorre sempre em mansa fluxão ao adiante:

Conhece acelerações que entusiasmam, e travagens que induzem sofrimento.

E há tempos de regressão:

Em que o «avanço» na hora apenas parece servir-nos «retrocesso» nas travessas.

Não é castigo dos deuses pela pressa: quiseste ir longe demais, agora tens que voltar para trás.

Nem fatalidade circular do alcatruz das noras: porque nunca é o «mesmo» que retorna, numa putativa «restauração» do passado.

Os chamados «tempos de regressão têm génese no aparecimento (de que importa empreender o estudo), dispõem de razões que lhes aconchegam a persistência (às quais importa conferir atenção), e - por mais que nos queiram do contrário convencer - não são irremovíveis (pelo que importa lutar).

Certos aparelhos - sintonizados com a programação uniformista do pronto-a-pensar hegemónico - gostam de difundir que nunca existiu, ou, então, que já acabou.

Outros olhares - espevitados somente pela gritaria do alvoroço - reconhecem-na apenas no agonismo mais agudizado das confrontações.

Mas a verdade é que a luta das classes não constitui um rótulo de propaganda "subversiva», nem bicho-papão para infundir medo aos timoratos, mas ingrediência social intrínseca daquele modo rasgado do ser que nas dominantes condições hodiernas de exploração do trabalho se produz:

Empapa o caldo das avançadas, das estagnações, e dos recuos, na configuração do nosso acontecer histórico colectivo.

$\mathrm{E}$ não tem apenas hora marcada naqueles momentos de entrevista em que dela flagrantemente nos damos conta.

As contradições estão lá: no torcido corpo das realidades que contorcem.

São a moldura, e o molde, daquilo que à superfície do visível, imediatamente recortado, nos aparece. 
Desenham a pista de obstáculos no movimento das labutas.

E definem um roteiro de respiração aos combates.

É tendo por andaime uma matriz estruturante capitalista que se mantém - com variedade embora no reportório das vestimentas em desfile exibidas - que o apercebido "retrocedimento» na esfera social e política se manifesta.

Recordo-lhe alguns vectores notórios, e notados.

Sem preocupações de hierarquia no elenco, nem intentos de completude no enunciado:

1. Uma asfixia - orçamentadamente induzida - das políticas públicas.

Muito em especial, nos domínios da educação, da saúde, da segurança social, do encurtamento das assimetrias, da cultura.

Escavando, e alargando - meticulosamente -, o barranco que separa a faixa dos "solventes» (entretanto, sobre-extorquidos nas camadas baixas e médias) do contingente geral dos «desprotegidos» (à mercê dos fados cada vez mais entregues).

2. Um transvase crescente - e à fartadela - do desempenho de funções estatais de soberania para consórcios privados, ou para entidades a um regime privatístico submetidas:

Com a correlativa transferência de fundos públicos - oriundos da tributação de todos, ainda que com um agravamento da desproporcionalidade no esforço contributivo exigido, em benefício só de alguns - para o bolso (sem fundo) de «empreiteiros» que embolsam as rendas.

Consagra-se, dest'arte - e por estes artifícios -, o caricato "princípio» da cartilha trivial, de que, à intocável "privatização» dos lucros, haverá de corresponder no balanço uma indiscriminada «socialização» dos prejuízos.

3. Uma ofensiva concertada - e sistemática - contra qualquer movimento social consequentemente empenhado na defesa e promoção colectivas dos interesses de quem trabalha (contratos, salários, duração da jornada de trabalho, licenciamentos, higiene e segurança, etc.):

Com a simétrica "demonização» de tudo aquilo que cheire a sindicatos de classe, associativismo dos profissionais, e outras movimentações cívicas conexas.

Neste afã, a arquitectura das "leis» é pontualmente retocada pelos escribas a fim de abençoar a regalia dos potentados, e até o vocabulário também sofre umas cirúrgicas alterações semânticas pontuais:

«Des-regulamento» passa a querer dizer: regras em exclusivo ditadas pelo prisma do patronato e da finança;

«flexibilização» devém eufemismo para denotar uma zona opaca que se estende entre a precariedade no emprego ocasional, e o arbitrário despedimento simples;

"austeridade» converte-se numa manta de embrulho, e cobertura, para extorquir ao cidadão comum o pagamento dos desmandos, e malfeitorias, de especuladores e de negocistas, que entretanto ficaram destapados. 
Em suma, os «ajustes» são feitos à custa dos mesmos, e ajustados à ganância dos do costume...

4. Um incremento subtil da reciclada e velha indústria do fabrico e manipulação de toda uma gama de «artigos» -- de acessível consumo grupal - destinados:

a formatar as «cabeças» de um corpo obediente;

a mistificar ideias, sentimentos, atitudes, e anseios;

a canalizar as energias sociais para abrigados parques de recolha, onde, pela inibição liminar do malfadado exame crítico (declarado sem préstimo, nem serventia), se torne mais difícil um correcto entendimento da natureza, da origem, e dos meios de combater, os efeitos nocivos das regressões sentidas, falsamente apregoadas pelo alti-falante como «regeneradoras».

A batalha das "consciências» não é o teatro decisivo da campanha, mas importa também cuidar dela, para que as actuações não se tornem praticamente inócuas.

5. Uma desqualificação - generalizada, e peremptória - do campo da «política».

Aproveitando a carona do noticiário de encobertas traficâncias e de corruptivos comportamentos, que fixaram residência no aterro (insalubre) da falcatrua.

Ao que parece, a onda do moralismo «angélico» também rebenta afinal na praia dos «moralistas» (pouco, ou nada, «angelicais»).

Mas a pretensão dos - sem vergonha nenhuma - rotativamente «indignados» e «suspeitos» traz outro perigo na ponta, que é indispensável desmontar, e destruir:

O desincentivo genérico à participação - activa, informada, séria, exigente, e organizada dos cidadãos no debate, e na tomada a cargo, da «coisa pública».

O «populismo» pesca na água turva. Em que uma turba inebriada de fantoches dança ao compasso do "chefe», que, do mesmo passo, não passa de marioneta suspensa nos cordelinhos de quem explora a correografia, os bailarinos, e o bailarico.

Impõe-se, por isso, assentar, noutros alicerces, uma genuína mobilização cidadã do povo, na construção solidária do seu destino colectivo.

E a tarefa permanece em aberto...

\section{§ 5. Resistir.}

Perante este rol infausto de calamidades e de catástrofes, em que o "edifício» (talvez ainda em obras) parece desmoronar-se - com a assessoria diligente de um batalhão de serventuários domésticos, e de «maquinaria» importada -, o «convite» (silencioso, ou declarado) que nos sopram tem por endereço: a capitulação, o demissionismo, a desistência, o ensimesmamento na lamúria dos alheados, ou a passagem esporádica pelo desespero daquelas «exaltações» que aquecem fugazmente a alma, mas deixam tudo à volta tal como está. 
Quando não estão reunidas as circunstâncias, os meios, as forças, e a conjuntura do momento, para vencer, o caminho dos combativos é entretanto outro:

Resistir.

Resistir, mas aparelhando a pedra ao embasamento de uma possibilidade real para transformações que tragam no alvo a vitória.

Na resistência brilha a chama da chamada a um outro estado das coisas.

Mas não basta pensar nele, sonhar com ele, esperar por ele.

Estatuindo-lhe o pormenor das praças, a gala dos fardamentos, e o calendário das festividades; adormecendo na ilusão suave de um paraíso reencontrado, e com as reparações devidas; baixando o abalado braço, desnecessário perante uma fé inabalável no advento seguro (algum dia) de outra terra prometida.

Resistir, sim, mas na perspectiva de transformar.

Porque transformação do mundo não é encomenda confiada ao "utopismo», tão-pouco quanto resistência é entretenimento "terapêutico-ocupacional» para umas horas de tráfego com intensidade reduzida.

O novo, antes de surgir, tem que ser trabalhado.

Mesmo em condicionamentos que obrigam à resistência:

No estudo que traz compreensão ao acontecido, ao que está acontecendo, às brechas que, no presente, rasgam carreiros à feitura.

$\mathrm{Na}$ congregação organizada das forças que interpretam, densificam, e encarnam, a solidez viva do projecto do qual se tornam portadoras.

No travar das escaramuças que a pauta do dia suscite.

Sendo embora diminutos na dimensão, localizados na incidência, parcelares no alcance, estes pequenos combates (com critério escolhidos: na implantação, no foco, e na iniciativa) - que consolidam posições, ou melhoram a defesa, quando o avanço esteja vedado - fortalecem a marcha, e a coesão dos marchantes.

Com uma condição, que requer escrupuloso cumprimento:

Nunca sacrificar, à imediatez momentânea do "êxito" imaginado, a trajectória consequente a prosseguir no futuro do movimento.

A actividade revolucionária não se mede pelo taxímetro das frases inflamadas, nem se restringe às fases do vento em popa. Mora - e demora -, com a sua colorida paleta de dispositivos, na vicissitude dos tempos.

É por isso que são virtudes do revolucionário - mesmo em período de uma baixa das marés - a lucidez no propósito, a firmeza no gesto, a alegria no companheirismo, o empenho na transformação.

Mas também: a paciência trabalhada, e o trabalho da esperança. 


\section{§ 6. Educação da classe trabalhadora.}

A educação da classe trabalhadora -- bem como o ensino público, em geral - tem um passado glorioso de conquista, e um presente atribulado de refregas no meio, e pela frente.

Apesar do altruísmo de certas intenções «caritativas», e de apregoados discursos, não é nem nunca foi - uma dádiva filantrópica.

A contradição dos interesses em liça, e no horizonte da mira, jamais the desertou da circunstância.

Subjectivamente, a educação da classe trabalhadora - por tantos, tanto tempo, considerada um luxo desnecessário, e até uma iniciativa perigosa - interliga-se com as lutas (económicas, sociais, políticas, culturais) do movimento operário pela libertação dos múltiplos jugos que o oprimem.

Através dela, busca-se no saber - fundamentado na textura, e omnilateral nas focagens respaldo para uma emancipação humanamente enriquecida: de todos os seres humanos, e do ser humano todo.

Objectivamente, as modalidades institucionalizadas da formação de profissionais (inclusivamente, a um nível superior) foram-se articulando com as próprias exigências do desenvolvimento capitalista das forças produtivas.

Num sistema lábil de variáveis (mas que não dispõe de elasticidade indefinida), o constante motor da procura do lucro acicata revolucionamentos técnico-científicos de complexidade crescente, que requerem mão e cabeça qualificadas para a obra.

Daí que o paradigma, em regime capitalista observado, tenha por objectivo (não raro, inconfesso):

Preparar «pessoal» que saiba produzir com eficácia e de um modo eficiente - na hora, e no posto, que ao empregador convenha (e, aliás, só enquanto a este convier) -,

a fim de que a bombagem da mais-valia não sofra incomodativos descontos pela «incompetência» do trabalhador;

o qual, além disso, deverá sair da "escola» bem domesticado às disciplinas do "sistema», receber adequada vacinação contra as curiosidades malsãs (que servem de veículo a «ideias» perniciosas), e ficar ainda agradecido aos benfeitores que lhe venham a propiciar algum salário (metendo à algibeira o trabalho não-pago que ele de graça lhes oferece).

A educação especificamente dirigida às classes trabalhadoras continua, por sua vez, a carregar um passivo acumulado de discriminações negativas.

E entramos aqui na zona encoberta do "obsceno»: literalmente, de aquilo que, estando fora de cena, visa influenciar a acção que no palco se desenrola.

Refiro-me ao estigma (escondido, ou apenas sussurrado) de uma estratificação social que, de ordinário, faz companhia, em dispositivos institucionais de arquitectura variável, ao dualismo 
que bifurca as vias do ensino, roubando à diferença (socialmente justificada) a igual dignidade (de facto, não reconhecida).

Aqueles que são, ou pretendem ser, «mais qualquer coisa» estacionam de um lado da rua (em Portugal, a Universidade); aqueles que são, ou não têm condições para deixar de ser, «menos qualquer coisa» atravessam para o passeio da frente (em Portugal, o Politécnico).

$E$, deste modo, em «boa ordem», e observando o «respeitinho» devido, lá se vão reproduzindo, junto com as castas dominantes, as relações hegemónicas de dominação, do mesmo passo que com candura se declara promover assim a «mobilidade social» das «camadas intermédias».

Tudo isto, de resto, na reconfortante certeza de que abaixo ainda deve moirejar essa plebe obscura dos «indiferenciados»: dos formalmente "excluídos» da "educação formal», porque de muita outra coisa «escorraçados».

Temo que, no Brasil - embora noutras formas, e com outros percursos -, algo de semelhante também aconteça (mesmo quando alguma hipocrisia, disfarçada de decoro, mande que não seja muito referido).

Historicamente, se considerarmos o panorama europeu e norte-americano dos inícios do século XIX, a educação politécnica corresponde (e responde) a necessidades novas, e a problemas novos, colocados ao saber - e ao saber-fazer, em geral - pelo desenvolvimento, e pela complexificação, da vida económica e das actividades sociais.

As Escolas Politécnicas vão, com efeito, trabalhar domínios - de manifesto interesse social - que se situam fora das áreas tradicionalmente cobertas ao tempo pela Universidade. E vão cultivá-las com exigências, métodos, e perfis de formação, numa medida significativa, diferentes daqueles que constituíam a ronceira praxe universitária estabelecida.

O Politécnico faz outras coisas, e fá-las de outra maneira.

Mas não tem que o fazer, porque se destine a um outro "tipo» (menos bafejado) de pessoas.

A diferenciação - epistemológica, e, porventura, institucional - de Politécnico e de Universidade, no horizonte dos saberes, corresponde, se fôr correctamente entendida, a um alargamento, e a um enriquecimento, dos interesses sociais de formação superior.

Quanto à estratificação social - tanto em termos materiais efectivos, como no que toca ao seu rebatimento simbólico ao nível das representações - decisivo é lembrar alguma coisa que a alguns pouco agrada ouvir:

Em rigor, e basicamente, a estratificação social é determinada, não pelo directo teor das formações escolares recebidas, ou até pela natureza das funções profissionais desempenhadas, mas pelo modelo de relações sociais que se desprende de um modo determinado - sem rodeios, nem água benta: capitalista - de organizar e de efectivar a produção e a reprodução do viver.

Nas nossas sociedades, esta questão real é, sem dúvida, objecto de luta política e económica (escancarada, ou sorrateira), mas não é uma «decorrência», nem automática, nem forçosa, da formação politécnica como tal ou da formação universitária como tal. 
Ainda que - como convém não esquecer - as políticas que enquadram e regem o modelo não sejam de todo «inocentes», ou «neutras», no que diga respeito ao eventual robustecimento que se queira imprimir a essa "estratificação», que no alicerce do prédio mergulha as raízes.

Por conseguinte, atenta a circunstância, para lidar com esta instância, é à porta de outras circunstâncias que, na verdade, importa ir bater.

\section{$\S 7$. Coda.}

Mas a hora, entretanto, já bateu, e é tempo de rematar este descosido alinhavado de reflexões.

Com mais um pequeno complemento à entrada, que talvez venha a desvendar-nos o caminho da saída.

Nas mitologias do "pecado original», "o trabalho» é vendido a quem trabalha como "castigo», que justifica, e abençoa, o perpetuar multímodo da exploração.

Nas variantes profanas do ancestral mitema, a sacrossanta propriedade privada sobre os meios de produção desempenha análogo papel de "origem»: inquestionada e inquestionável. Vindo o «pecado mortal», por sua vez, a consistir em querer pôr essa propriedade em questão.

Haverá mitos que imaginam «explicar» altas coisas que se desconhecem.

Nestas «mitificações» há muito conhecidas, o "segredo» que as explica resolve-se numa mistificação chã dos imaginários.

O trabalho não é flagelo; é condição.

Mas não é forçoso que ele se exerça - como tormento, e como perda - nas condições forçadas do trabalho explorado: em que a mais-valia produzida é empalmada pelo explorador, sob a forma de lucro, e em que este lucro comanda, e subordina a si, a própria produção, a qual não visa de todo - ao invés do que a cada esquina nos repetem - satisfazer as «necessidades sociais».

É no trabalho, e por trabalho, que a humanidade

- convertendo as suas forças próprias (de inteligência com braço, e de braço inteligente) em instrumento socializado de realização enriquecedoramente desenvolvida do potencial comunitário de valências que vai criando - se emancipa dos constrangimentos que tolhem, remove as misérias que amesquinham, se humaniza: pelo cunho de qualidade que se torna capaz de imprimir à própria destinação do seu viver (colectivo, e singularizado), e à herança que como legado entrega ao desfiar das gerações.

A educação dá-se, e opera, na moldura de um viver.

De um viver, com assentamento numa circunstância, que pesa.

Mas tendo por constitutiva tarefa - e exigente desafio - dar uma volta aos pesos, transformando as circunstâncias. 
Em 1845, perante os desconsolos da altura que pareciam não ter remédio à vista, Marx e Engels observaram: "Se o ser humano é formado pelas circunstâncias, então, tem que se formar humanamente as circunstâncias.» .

Somos profissionais da arte de ensinar.

Saibamos prosseguir como aprendizes deste ofício do viver.

Fico a todos obrigado pela atenção com que me escutaram.

Lisboa, Março/Julho de 2017. 